\title{
Reliability and Safety of Vertical Transportation Use
}

\author{
Michail Stepanov ${ }^{1, *}$, Batraz Kaytukov ${ }^{1}$ and Ayub Mechiev ${ }^{1}$ \\ ${ }^{1}$ Moscow State University of Civil Engineering, Yaroslavskoe shosse, 26, Moscow, 129337, Russia
}

\begin{abstract}
At present the problem of vertical transport safety is crucial as it is evidenced by the statistical data on the number of accidents and injuries There are no regulatory requirements for permissible safety level of the elevator performance. service support system for the elevator is aimed at maintaining the performance standard level throughout the specified service life of vertical transportation. For the elevator equipment which is a technically complex system, hazard is manifested in the form of failure of various structural elements that affect safety. In this study the probability of a hazardous situation is characterized as risk-failure.
\end{abstract}

\section{Introduction}

At present there is a tendency for the increase in the number of elevators put into operation. During the operation of an elevator there is the probability of a hazardous situation $(P)$ and the process safety assurance is calculated by the given equation $(E)$ for a single situation. The known methods of reliability and risk theories allow us to do the tasks connected with both the risk assessment and the systems reliability and safety with the help of the calculation method [1-9].

The relevance of the research is justified by the need for the elevator operation reliability and accident prevention measures as well as the development of the ways both to enhance citizens safety on vertical transportation and to adjust the parameters of specified service life of various elevator elements.

In order to achieve the above objectives it is necessary to accomplish the following tasks: to analyze malfunctions and identify the elements that affect safety of the elevator, to make cluster analysis, to develop a method for assessing the safety level.

The risk analysis is represented by a sequence of logical steps providing a systematic approach to identifying hazards associated with the operation of elevators. While processing statistical data the method of cluster analysis has been used, which allows decomposing the elevator into component units and elements depending on the malfunction mode, the reasons for the malfunction and the location of the equipment in the elevator.

\footnotetext{
* Corresponding author: masmias@mail.ru
} 


\section{Methods}

This method allows you to determine the contribution to risk - safety, taking into account ranks and hazards. Based on the statistical data processing results the dependence of the number of failures on specified service life has been determined and the dependence graphs for the cabin door, shaft door, drive system and equipment have been plotted. The proposed method for assessing elevator operation safety has made it possible to determine safety level for different service life periods and at the same time to determine the dependence of the elevator safety level on the service life of the particular elevator. This method of the resource indicator adjustment allows both reducing the expenditures involved in safe operation of the elevator and increasing the safety level of citizens movement on vertical transportation.

Table 1. Summary statistical data on Kone elevators

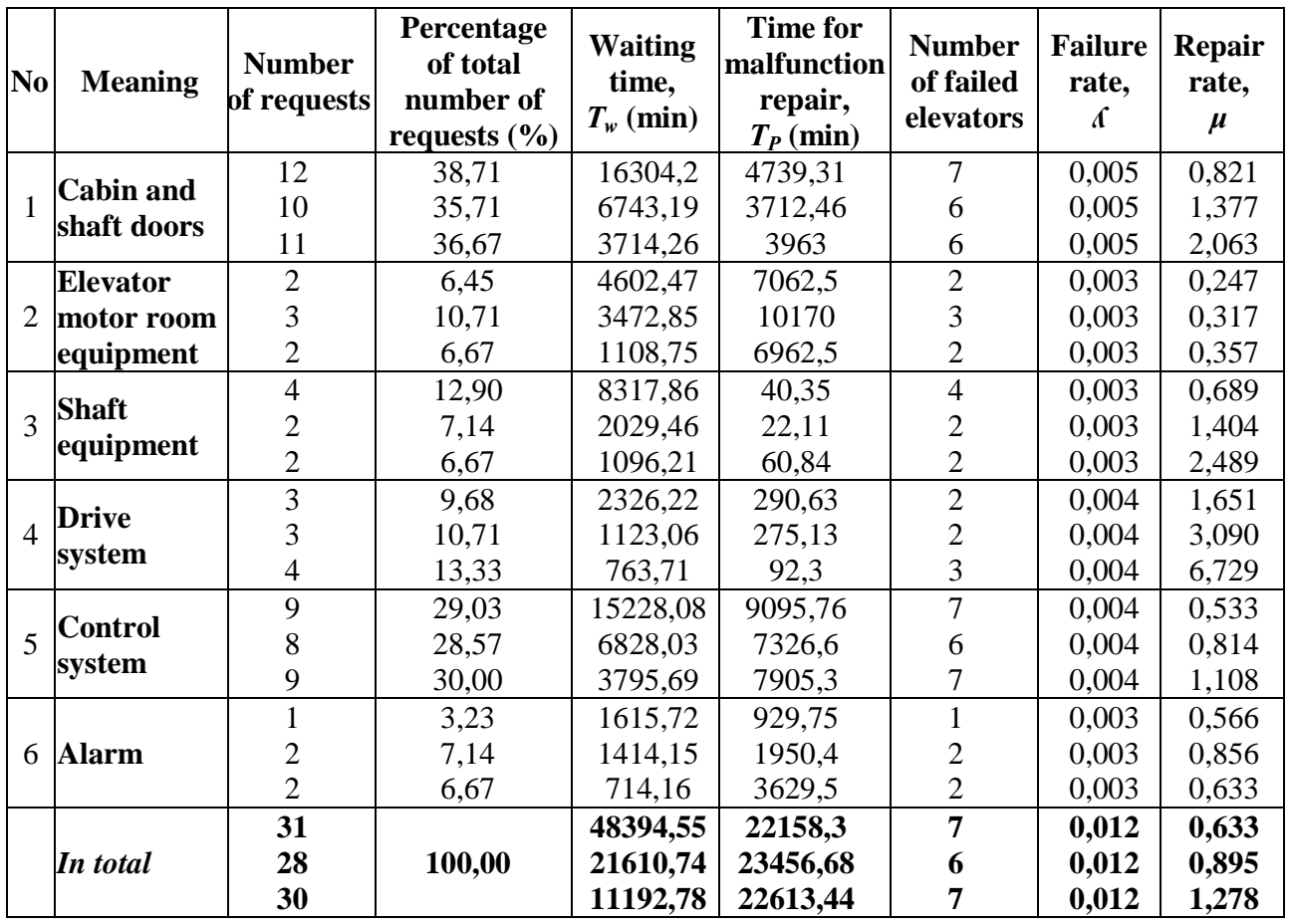

A constantly growing need in elevators stimulates the process of the design improvement of elevators and their elements. However, the increasing fleet of elevators requires quality improvement of the installation technology and maintenance and repair systems in order to enhance reliability and safety of vertical transportation use. In accordance with the regulations to ensure safety of the elevator operation throughout the specified service life the following requirements must be met: the use of the elevator according to the intended purpose; carrying out inspections; maintenance and repair of elevators. The elevator maintenance system can be represented in the form of a queuing system, which represents servicing continuous repair requests (elevator failures) coming at the rate of $\kappa$. The repair requests are serviced for a certain period of time by the service facility (electromechanician) at the rate of $\mu$. It makes sense to apply the method of cluster analysis when processing statistical data on elevator failures, waiting repair time and malfunction repair. This approach allows decomposing the elevator into component units 
and elements, depending on the malfunction mode, the reasons for the malfunction and the location of the equipment in the elevator. When accomplishing the tasks connected with safety improvement, the hierarchical method of clustering proved to be remarkably effective. The advantage of this method is in visibility and connection to constructing a tree-like scheme - a dendrogram. The elevator equipment clustering method involves combining elevator units into clusters in accordance with the functional purpose. For example, elevator units such as cabin and shaft doors, control system, elevator guide tracks are combined into a common cluster representing the elevator in question.

The statistical data on the operation of Kone elevators with weight-carrying capacity of $1000 \mathrm{~kg}$ were obtained from three facilities in operation in Moscow, henceforth referred to as facilities No. 1, No. 2, No. 3. The processing of the statistical data has allowed carrying out cluster analysis and decomposition of the elevator into component units and elements. Based on the analysis of the failures of the elevators operated at the facilities No. 1, No. 2 and No. 3, the most problematic components affecting safe operation were identified. The cabin and shaft doors account from $35 \%$ to $38 \%$ failures, the control system accounts from $28 \%$ to $30 \%$ failures. The results of the statistical processing of the data on Kone elevators operation are presented in the summary table 1.

Table 2. Repair waiting time from. repair rate

\begin{tabular}{|l|c|c|c|}
\hline Repair waiting time $\boldsymbol{T}_{\boldsymbol{w}}, \boldsymbol{h}$ & 6,21 & 12,9 & 26,03 \\
\hline Repair rate, $\boldsymbol{\mu}$ & 1,278 & 0,859 & 0,633 \\
\hline
\end{tabular}

According to the obtained data on the average waiting repair time and corresponding elevator repair rates, Table 2 has been compiled, the dependence has been plotted (Fig. 1). The method of least squares data fitting shows the power mode of the change in repair waiting time and malfunction repair rate (Fig. 1).

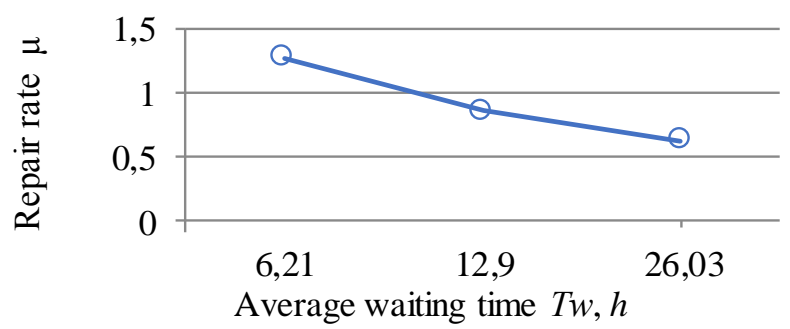

Fig. 1. Dependence of the repair rate $\mu$ on waiting time $T_{w}$

The equation of the approximated dependence (fig. 1) is

$$
y_{l}=3,0909 x_{l}^{-0,491},
$$

where $x_{1}$ is average repair waiting time $T_{w}, h$;

$y_{1}$ is repair rate $\mu$.

According to Table 1 (for facility No. 1) the contribution of each element $b_{i}$ to the risksafety has been determined, it corresponds to the percentage of the repair requests for failure of certain elevator elements. This is the data on 1 year elevator operation. At the facility there are 10 elevators. Taking into consideration the fact that the elevator is repaired by one electromechanician and the cost of one hour is the same for all the elevator elements, the repair cost rank can be determined by the formula: 


$$
r_{i}=\frac{T w_{\mathrm{i}}+T p_{\mathrm{i}}}{\sum_{\mathrm{i}}^{\mathrm{n}}(T w+T p)}
$$

where $T_{w i}$ is repair waiting time for $i$ th element;

$T_{p i}$ is repair time of $i$ th element;

$T_{w}$ is total repair time for all the elements.

Then the hazard risk $P_{i}$ is determined by the formula:

$$
P_{i}=b_{i} \cdot r_{i} .
$$

The obtained values of the contributions to the safety-risk $b_{i}$, ranks $r_{i}$ and hazard risks $P_{i}$ are summarized in Table. 3 .

Table 3. The number of the elevator element, corresponding safety risk values, ranks, hazard risk and component safety level

\begin{tabular}{|c|c|c|c|c|}
\hline $\begin{array}{c}\text { Element } \\
\text { number }\end{array}$ & $\boldsymbol{b}_{\boldsymbol{i}}$ & $\boldsymbol{r}_{\boldsymbol{i}}$ & $\boldsymbol{P}_{\boldsymbol{i}}$ & $\boldsymbol{E}_{\boldsymbol{i}}$ \\
\hline 1 & 0,3871 & 0,3 & 0,12 & 0,88 \\
\hline 4 & 0,0645 & 0,165 & 0,01 & 0,99 \\
\hline 5 & 0,129 & 0,18 & 0,02 & 0,98 \\
\hline 7 & 0,0961 & 0,037 & 0,004 & 0,996 \\
\hline 8 & 0,2903 & 0,347 & 0,1 & 0,9 \\
\hline 9 & 0,0323 & 0,036 & 0,001 & 0,999 \\
\hline
\end{tabular}

According to the data from the table 3, elevator safety level is

$$
\begin{aligned}
E= & \left(1-P_{1}\right)\left(1-P_{4}\right)\left(1-P_{5}\right)\left(1-P_{7}\right)\left(1-P_{8}\right)\left(1-P_{9}\right)= \\
& =0,88 \times 0,99 \times 0,98 \times 0,996 \times 0,9 \times 0,999=0,765
\end{aligned}
$$

In order to determine the safety level of the elevator and the corresponding operationability factor at the facility under consideration where there are 10 elevators, the safety level values for different quantities of serviced elevators and corresponding operationability factors have been determined according to the graph (Fig.1).

Safety level values are determined by the dependence:

$$
E_{i}=\frac{E_{10}+K_{r i}}{K_{r 10}}
$$

where $E_{10}$ is safety level value, which is 0,765 , for 10 elevators; $K_{r i}$ is operationability factor for 10 elevators.

With the help of the monitoring system E-Link developed by Kone, operating time of the elevators has been determined, which is presented in Table. 4.

Table 4. Elevator operating time

\begin{tabular}{|c|c|}
\hline Number of storeys & Operating time, $\boldsymbol{h}$ \\
\hline $4-6$ & 2,75 \\
\hline $7-9$ & 3,5 \\
\hline $10-15$ & 4,5 \\
\hline $16-34$ & 6,25 \\
\hline
\end{tabular}


Using the elevator safety level values for the facilities under consideration, which make up 0,765 for facility № 1 - 0,747 for facility № $2-0,729$ for facility № 3, the graphs of the dependences of the safety level on elevator operating time have been plotted, taking into account the fact that the operating time for the given elevator is 4, 5 hours (Fig 2).

The equation of the approximated curve for facility № 1 is:

$$
y_{1}=1,6005 x^{-0,487},
$$

for facility №2 it is:

$$
y_{2}=1,5868 x^{-0,501},
$$

for facility №3 it is:

$$
y_{3}=1,4934 x^{-0,479} .
$$

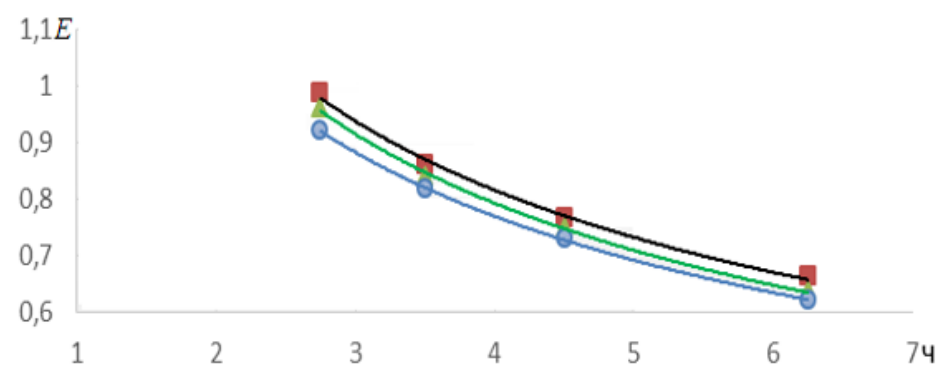

Fig. 2. The dependences of elevator safety level on elevator operating time for facilities №1, №2, №3

Based on the results of the survey of the engineering systems and some structural units at the facilities where elevators are operated (Moscow), the dependence of the number of failures on elevator service lifetime has been determined.

$$
y=1,5 x^{2}-12,4 x+28,7
$$

where $y$ is the number of failures;

$x$ is service lifetime, $y$.

Considering the average service life of the cabin and shaft doors, elevator motor room equipment, shaft equipment, drive system, control and alarm system, the graphs of various components, the number of failures for different service life periods has been determined. The number of failures for different elevator components and service life periods has been determined and summarized in Table 5.

Table 5. Summary data of failures for different service life cycles of components

\begin{tabular}{|l|c|c|c|c|c|c|}
\hline \multicolumn{1}{|c|}{ Component } & 5 years & 10 years & 12,5 years & 15 years & 20 years & 25 years \\
\hline Cabin and shaft doors & 1,7 & 21,2 & 41,92 & 2,74 & 7,8 & 41,92 \\
\hline Motor room equipment & 0,29 & 3,5 & 6,9 & 11,48 & 0,29 & 3,5 \\
\hline Shaft equipment & 0,58 & $7,85,34$ & 15,65 & 26,5 & 0,58 & 7,8 \\
\hline Drive system & 0,43 & 5,34 & 10,52 & 17,68 & 37,33 & 64,39 \\
\hline Control system & 1,3 & 15,9 & 31,55 & 2,09 & 5,8 & 31,55 \\
\hline Alarm system & 0,14 & 1,76 & 3,46 & 0,2 & 0,64 & 3,46 \\
\hline
\end{tabular}


In accordance with the National State Standard 55964, the average service life of the cabin and shaft doors is 12,5 years, it is 15 years for the elevator motor room and shaft equipment, it is 25 years for the drive system, it is 12,5 years for the control and alarm systems.

When optimizing elevators the level of safety for all the service life cycles has been determined on the basis of the safety assessment method and the elevator safety level dependence has been set up, it is the fourth power and polynomial. The equations of the approximated curve (Fig. 3) is:

$$
y=0,00003 x^{4}-0,0015 x^{3}+0,0266 x^{2}-0,18848 x+1,2013 .
$$

The approximation reliability value $R^{2}=0.99986$.

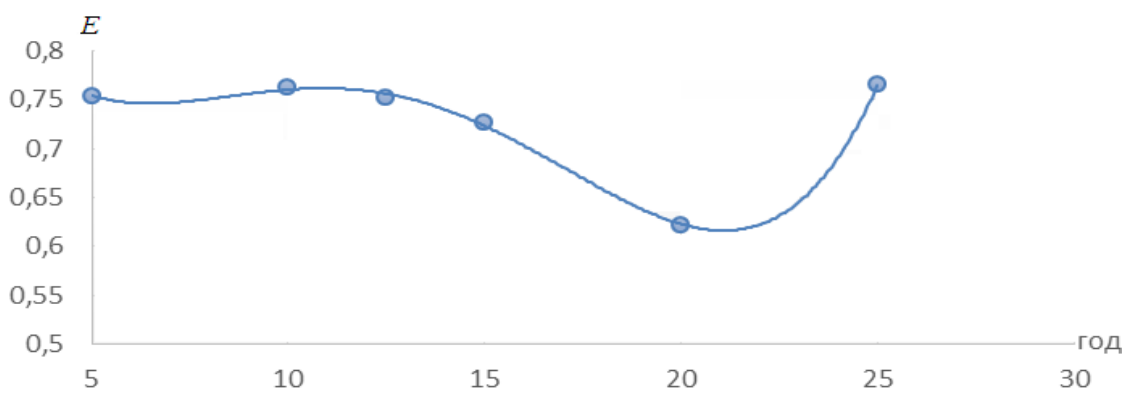

Fig. 3. The dependence of the elevator safety level on the elevator service life

\section{Conclusions}

1. The proposed method for assessing the elevator safety allows identifying the most problematic elevator elements which require special attention during operation on the one hand and a set of spare parts on the other hand.

2. The application of this method justifies the modernization of the elevator (after 15 years of operation) and adjusts the average service life of individual elements of the elevator.

3 . The level of the elevator safety during operation is determined depending on the service life.

\section{References}

1. V. A. Zorin, V. A. Daugello, N. S. Sevryugina, IBGTU (2009)

2. N. S. Sevryugina, IBGTU ( 2012)

3. N. S. Sevryugina, M. A. Stepanov, A. V. Mechiev, Mec. Con. 78. 4. (2017)

4. M. A. Stepanov, A. V. Mechiev, SR. 3. (2016)

5. V. I. Telichenko, S. I. Zavalishin, M. S. Hlystunov, MGSU, (2005)

6. N. I. Baurova, V. A. Zorin, V. M. Prikhodko, Pol. S. 9. 2. (2016)

7. A. A. Volkov, V. M. Roytman, L.A. Shilova, IJAER. 11. 3. (2016)

8. N. S. Sevryugina, M. A. Stepanov, ICJ. 7. (2017)

9. YU. A. Verigin, S. V. Tolstenev, A. IAltGTU, (2007)

10. YU. I. Polyakov, VRC. 2. (2008) 